\title{
Seedling growth of 2 Leucaena species
}

\author{
RANDY L. DOVEL, DONALD M. VIETOR, AND MARK A. HUSSEY
}

\begin{abstract}
Authors are former graduate research assistant (presently assistant professar, Crop and Soil Science Department, Oregon State University, Corvallis 97331); and associate professor and associate professor. Texas Agricultural Experiment Station, Texas A\&M University, College Station 77843.
\end{abstract}

\section{Abstract}

Seed of Leucaena leucocephala (Lam) Dewit variety K-8 and $L$. retusa Gray variety Yellow Puff were germinated in growth chambers maintained at $10,25,30$, and $35^{\circ} \mathrm{C}$. A fifth treatment of $30^{\circ} \mathrm{C}$ for 13 hours followed by $25^{\circ} \mathrm{C}$ for 11 hours was also included. Seed were monitored every 4 days for 16 days for percent germination, testa weight, cotyledon weight, hypocotyl weight and length, and radicle weight and length. Yellow Puff exhibited higher maximum germination and a higher germination rate (expressed as percent of germinable seed germinated 4 days after imbibition) than K-8. There was no temperature effect on maximum germination of K-8, while the $35^{\circ} \mathrm{C}$ treatment substantially reduced germination in Yellow Puff. Despite faster germination, Yellow Puff seedlings elongated slower compared to K-8. Radicle/hypocotyl ratios were similar for both species across all temperatures. Due to heavier seed weight of K-8 than Yellow Puff, testa and cotyledon weights were also heavier. Rate of nutrient reserve mobilization from the testa and cotyledon increased with increasing temperature in $\mathrm{K}-8$, while rate of mobilization of nutrient reserves in Yellow Puff seed declined at temperatures above $30^{\circ} \mathrm{C}$.

Key Words: Leucaena leucocephala, Leucaena retusa, little leaf leadtree, seedling vigor, establishment

Leucaena leucocephala (Lam) Dewit is reported to be one of the fastest growing trees in the world. Yearly biomass accumulations of greater than $12,500 \mathrm{~kg}$ dry matter ha ${ }^{-1}$ have been reported (Jones and Bray 1982). Estimates of symbiotically fixed nitrogen range from 110 to $600 \mathrm{~kg} \mathrm{~N} \mathrm{ha}^{-1}$ (Holliday and Somasegaran 1982). Despite these impressive production characteristics, the use of Leucaena species has been hampered by difficulties in establishment (Jones and Bray 1982). The slow initial top growth reported for $L$. leucocephala and other species may be due to a lack of energy from seed reserves or photosynthesis, or to partitioning a large proportion of the energy to the root system. This study was conducted to quantify the amount of seed reserves available for growth and partitioning of these resources in dark grown Leucaena seedlings.

Two species, L. leucocephala and $L$. retusa, were included in this study. Leucaena leucocephala is a native of northern Mexico. Cultivar $\mathrm{K}-8$, the variety included in this study, was developed in Hawaii and is not recommended for use in areas receiving less than $1,000 \mathrm{~mm}$ of annual precipitation. In contrast, little leaf leadtree (Leucaena retusa Gray) is a native of the western part of the Edwards Plateau and Trans-Pecos regions of Texas, as well as the state of Coahuila, Mexico (Correll and Johnson 1970). Average annual rainfall in its region of adaptation is 200 to $300 \mathrm{~mm}$. The cultivar Yellow Puff was selected in Uvalde, Texas, where a similar rainfall pattern prevails. Whisenant et al. (1985) concluded that little leaf leadtree had the greatest potential among woody range

Manuscript accepted 28 Apr. 1993. legumes for increasing browse availability in the Sonoran and Chihuahuan deserts. The germination and seedling growth characteristics of little leaf leadtree appear to be very similar to those of $L$. leucocephala (Whisenant and Ueckert 1982).

Low seedling vigor hampers the growth of several forage legumes. Work by breeders to improve seedling vigor in small seeded forage legumes has shown an overall correlation of seedling vigor to seed size (Townsend 1979, Beveridge and Wilsie 1959, Carleton and Cooper 1972). Leucaena seed are polymorphic with seed at the tip of the pod being lighter than those at the base (Pathak et al. 1974). Gupta et al. (1983) found seed size was positively correlated to field emergence and growth rate of $L$. leucocephala seedling of Cunningham line-3. The faster seedling growth from large compared to small seed was attributed to the presence of greater cotyledonary reserves (Pathak et al. 1974).

By quantifying the mobilization of seed reserves in seedlings grown in darkness, the amount of reserves available to the embryo for seedling growth may be determined. The measurement of partitioning of seed reserves between the radicle and hypocotyl in dark grown seedlings would represent the partitioning of seed reserves only, without the confounding of seed reserves and photosynthate partitioning as would be the case in light grown seedlings.

This study was conducted to quantify the mobilization and distribution of seed nutrient reserves through the use of dark grown seedlings. This experiment tested the hypotheses that seed nutrient reserves are not sufficient to provide the resources required for emergence and development of a vigorous, autogenous seedling, and that the seed nutrient reserves are partitioned largely to the radicle in young Leucaena seedlings, resulting in poor shoot growth.

\section{Materials and Methods}

Seeds of $L$. retusa, variety Yellow Puff (obtained from the Soil Conservation Service, South Texas Plant Material Center in Kingsville) and the K-8 variety of $L$. leucocephala (obtained from Trees International) were separated into various sized seed lots using a screen separator. Only seed passing through a 14-mesh screen (8.0-mm openings), but not a 12-mesh screen (7.2-mm openings), were used in this experiment. The seed were germinated at 4 constant temperatures: $20,25,30$, and $35^{\circ} \mathrm{C}$. A fifth treatment alternated between 30 and $25^{\circ} \mathrm{C}$ for 13-hour light-period and 11-hour dark-period, respectively. Seed were scarified by soaking in concentrated sulfuric acid for $15 \mathrm{~min}$. and rinsed 3 times with distilled water.

Twenty-five seed were placed on germination paper and covered with a light strip of cotton to secure the seed. Four sheets of germination paper with the seed and cotton in place were stacked, one on top of the other, and rolled together to form a germination roll. Each roll was placed in a $38-\mathrm{cm}$ length of $5-\mathrm{cm}$ PVC pipe. After the bottom of the tube was capped, $120 \mathrm{ml}$ of distilled water was added to the wet roll. After capping the tops, the assembled 
tubes were placed in growth chambers at the appropriate temperature treatments.

A germination roll for each seed lot and temperature treatment was harvested every 4 days for 16 days, the study being repeated in time. After germination counts had been taken, length and dry weight of radicle and hypocotyl were recorded. Germination rate was calculated by dividing the germination percentage 4 days after imbibition by the maximum germination percentage (which is assumed to be the percentage of germinable seed). Dry weights of the testa and cotyledons were also measured following drying for 72 hours in a forced air drier at $55^{\circ} \mathrm{C}$. The testa included both the testa and endosperm; the endosperm adhered tightly to the testa and was difficult to remove. Seed nutrient reserve mobilization was characterized by observing the decline in the sum of testa and cotyledon. Testa weight was included in the testa fraction in the form of galacto-mannons. Analysis of variance was utilized to define the effect of temperature, species, and time (days after imbibition) on germination and seedling growth parameters with a split-split plot design (Hicks 1982). All percent data were transformed by arcsin transformation before analysis to insure normal distribution of data. Temperature was the whole plot, species was the split plot, and time was the split-split plot. Unless otherwise stated, statistical significance was tested at the 0.05 level of probability. Mean separations were tested using a LSD method.

\section{Results and Discussion}

Yellow Puff had a higher maximum germination percent than $\mathrm{K}-8$ at all temperatures except $35^{\circ} \mathrm{C}$ (Table 1). A greater number of

Table 1. Germination rate and maximum germination of Leucaena leucocephala variety $K-8$ and $L$. retusa variety Yellow Puff as affected by temperature.

\begin{tabular}{lccc}
\hline \hline Variety & Temperature & $\begin{array}{c}\text { Germination } \\
\text { rate }^{1}\end{array}$ & $\begin{array}{c}\text { Maximum } \\
\text { germination }\end{array}$ \\
\hline \multirow{3}{*}{ K-8 } & $\left.{ }^{\circ} \mathrm{C}\right)$ & $(\%)$ & $(\%)$ \\
& 20 & 9.1 & 47 \\
& 25 & 16.8 & 41 \\
& $30 / 25$ & 35.7 & 48 \\
& 30 & 32.3 & 53 \\
Yellow Puff & 35 & 24.5 & 41 \\
& 20 & 22.5 & \\
& 25 & 67.1 & 83 \\
& $30 / 25$ & 79.0 & 71 \\
& 30 & 91.1 & 71 \\
LSD (0.05) & 35 & 50.2 & 46 \\
\hline
\end{tabular}

${ }^{1}$ Germination rate was calculated as the percent of germinable seed germinated 4 days after imbibition.

hard seed after scarification for K-8 compared to Yellow Puff may partly explain lower maximum germination percent for $\mathrm{K}-8$. The maximum germination percent of K-8 was not affected by the range of temperatures in this study. In contrast, the maximum germination percent of Yellow Puff was significantly lower at $35^{\circ}$ $\mathrm{C}$ than at the other temperature treatments (Table 1). Whisenant and Ueckert (1982) found that the maximum germination percent of Yellow Puff was significantly reduced after 10 days at temperatures above $30^{\circ} \mathrm{C}$. This species by temperature interaction could reflect the adaption of K-8 and Yellow Puff to different temperature regimes.

Yellow Puff exhibited the faster germination rates with an average of $62 \%$ of the germinable seed germinated by day 4 , compared to only $24 \%$ for K-8 (Table 1 ). Increasing temperatures from $20^{\circ}$ to $30^{\circ} \mathrm{C}$ increased the germination rates of both species; however, the $35^{\circ} \mathrm{C}$ treatment decreased germination rates to a lower level than all other temperatures except $20^{\circ} \mathrm{C}$ (Table 1). The $30 / 25^{\circ} \mathrm{C}$ treatment resulted in germination rates intermediate to the $30^{\circ}$ and $25^{\circ} \mathrm{C}$ treatments.

The faster germination rates of Yellow Puff may reflect not only differences in seed quality, but also differences in adaptation. The rapid germination of Yellow Puff may be due to adaptation to a xeric environment where rapid germination and establishment following infrequent rains could favor survival.

Despite lower maximum germination percent and germination rates, K-8 seedlings were longer than those of Yellow Puff throughout the study (Table 2). This may be accounted for, in part, by the greater amount of reserves and larger seed weight for K-8.

Table 2. Total seedling length (cm) of Leucaena leucocephala variety K-8 and $L$. retusa variety Yellow Puff seedlings as affected by temperature and time of imbibition.

\begin{tabular}{lccccc}
\hline \hline \multirow{2}{*}{ Variety } & \multirow{2}{*}{$\begin{array}{c}\text { Temper- } \\
\text { ature }\end{array}$} & \multicolumn{4}{c}{ Time of imbibition (Days) } \\
\cline { 3 - 6 } K-8 & $\left({ }^{\circ} \mathrm{C}\right)$ & $\mathbf{4}$ & 8 & 12 & 16 \\
\hline \multirow{4}{*}{ Yellow Puff } & 20 & 1.1 & 5.6 & 9.6 & 12.7 \\
& 25 & 2.9 & 6.9 & 10.4 & 10.3 \\
& $30 / 25$ & 5.5 & 13.9 & 17.9 & 19.8 \\
& 30 & 7.4 & 12.4 & 15.8 & 24.1 \\
& 35 & 5.3 & 9.1 & 12.1 & 13.9 \\
& 20 & 0.7 & 3.5 & 4.3 & 5.7 \\
& 25 & 1.9 & 5.0 & 6.7 & 7.1 \\
& $30 / 25$ & 4.1 & 8.8 & 9.9 & 6.3 \\
$\operatorname{LSD}(.05)=3.3$ & 30 & 3.2 & 8.7 & 11.5 & - \\
& 35 & 2.4 & 4.1 & 2.5 & - \\
& & & & & \\
\hline
\end{tabular}

Temperature significantly affected seedling elongation with both species responding similarly to the range of temperatures in this study (Table 2). Seedling elongation rates of K-8 increased with increasing temperature up to $30^{\circ} \mathrm{C}$, but declined as germination temperatures rose to $35^{\circ} \mathrm{C}$ (Table 2). Yellow Puff seedling elongation rates followed the same trend but differences were not significant at day 4. This agrees with Whisenant and Ueckert (1982) who reported shorter radicle lengths for Yellow Puff 10 days after imbibition for germination temperatures exceeding $30^{\circ} \mathrm{C}$. Seedling length of K-8 increased throughout the study while seedling elongation of Yellow Puff proceeded at a slower rate than K-8. Cessation of elongation of Yellow Puff seedlings after day 12 was probably due to depletion of nutrient reserves. Most of the early germinating plants of Yellow Puff were dead by day 16. At the 16 day harvest, the majority of surviving seedlings were those that were slow in germinating and were shorter than early germinating seedlings. Since only live, healthy seedlings were measured, seedling length of Yellow Puff appeared to decline between days 12 and 16.

The 3 tests of seed quality yielded variable results. Although Yellow Puff seeds germinated best, K-8 seedlings exhibited greater elongation rates. For comparison of the seedling vigor of the 2 seed lots, the rate of seedling elongation may most accurately estimate the performance of seedlings in the field. Cooper et al. (1980) found that seedling length 3 days after germination was correlated to yields of greenhouse grown cicer milk-vetch seedlings and forage yield obtained in the field.

The lack of correlation between germination rates and seedling elongation rate may be related to a difference in the storage and mobilization of seed reserves in K-8 and Yellow Puff. Nutrient 
reserves in Leucaena spp. seed are primarily in the cotyledons and endosperm. The endosperm surrounds the cotyledons and consists largely of galacto-mannons, complex polysacharides of galactose and mannose (Lesniak and Liu 1981). The galacto-mannons are readily broken down by galactosidase and mannosidase secreted by the aleurone layer and absorbed by the cotyledons (Reid and Meier 1973). The endosperm adheres tightly to the testa and was included in the testa fraction due to difficulties in separating the 2 plant parts. The mobilization of reserves from the endosperm into the cotyledons of germinating $\mathrm{K}-8$ seeds was quite rapid as evidenced by the decline in testa weight between day 0 and day 4 . In contrast, testa weight of Yellow Puff did not drop to levels significantly lower than day 0 until day 8 at $35^{\circ} \mathrm{C}$, day 12 at $25^{\circ}$ and $30^{\circ}$ $\mathrm{C}$, and day 16 at $20^{\circ} \mathrm{C}$ (Table 3).

Table 3. Testa, cotyledon, and testa plus cotyledon weight (mg seedling ${ }^{-1}$ ) of Leucaena leucocephala variety K-8 and $L$. retusa variety Yellow Puff seedlings as affected by temperature and time of imbibition.

\begin{tabular}{|c|c|c|c|c|c|c|}
\hline \multirow[b]{2}{*}{ Variety } & \multirow{2}{*}{$\begin{array}{l}\text { Tempera- } \\
\text { ture }\end{array}$} & \multicolumn{5}{|c|}{ Days of inbibition } \\
\hline & & 0 & 4 & 8 & 12 & 16 \\
\hline Testa weight & $\left({ }^{\circ} \mathrm{C}\right)$ & \multicolumn{5}{|c|}{$\ldots\left(\mathrm{mg}\right.$ seedling $\left.{ }^{-1}\right) \ldots \ldots$} \\
\hline K-8 & $\begin{array}{c}20 \\
25 \\
30 \\
35 \\
30 / 25\end{array}$ & $\begin{array}{l}26.7 \\
26.7 \\
26.7 \\
26.7 \\
26.7\end{array}$ & $\begin{array}{l}20.8 \\
18.7 \\
18.2 \\
17.5 \\
19.4\end{array}$ & $\begin{array}{l}19.6 \\
17.6 \\
16.4 \\
14.9 \\
16.1\end{array}$ & $\begin{array}{l}17.4 \\
14.5 \\
17.9 \\
14.1 \\
17.0\end{array}$ & $\begin{array}{l}18.0 \\
13.3 \\
15.8 \\
15.5 \\
13.7\end{array}$ \\
\hline Yellow Puff & $\begin{array}{l}20 \\
25 \\
30 \\
35\end{array}$ & $\begin{array}{l}16.8 \\
16.8 \\
16.8 \\
16.8\end{array}$ & $\begin{array}{l}16.1 \\
16.3 \\
15.2 \\
15.8\end{array}$ & $\begin{array}{l}15.3 \\
13.4 \\
14.7 \\
11.0\end{array}$ & $\begin{array}{r}14.7 \\
8.4 \\
11.9 \\
3.1\end{array}$ & $\begin{array}{r}12.9 \\
8.1 \\
- \\
-\end{array}$ \\
\hline \multicolumn{7}{|l|}{$\operatorname{LSD}(0.05)=3.9$} \\
\hline $\begin{array}{l}\text { Cotyledon weigh } \\
\text { K-8 }\end{array}$ & $\begin{array}{c}20 \\
25 \\
30 \\
35 \\
30 / 25\end{array}$ & $\begin{array}{l}24.6 \\
24.6 \\
24.6 \\
24.6 \\
24.6\end{array}$ & $\begin{array}{l}25.5 \\
27.0 \\
22.4 \\
23.2 \\
24.2\end{array}$ & $\begin{array}{l}24.1 \\
19.7 \\
17.8 \\
13.0 \\
16.9\end{array}$ & $\begin{array}{l}21.0 \\
15.5 \\
13.8 \\
10.8 \\
14.0\end{array}$ & $\begin{array}{r}17.3 \\
15.2 \\
11.0 \\
7.9 \\
11.6\end{array}$ \\
\hline Yellow Puff & $\begin{array}{c}20 \\
25 \\
30 \\
35 \\
30 / 25\end{array}$ & $\begin{array}{l}21.1 \\
21.1 \\
21.1 \\
21.1 \\
21.1\end{array}$ & $\begin{array}{l}22.5 \\
18.2 \\
15.4 \\
16.8 \\
15.5\end{array}$ & $\begin{array}{r}14.1 \\
10.6 \\
10.3 \\
6.0 \\
12.0\end{array}$ & $\begin{array}{r}12.9 \\
6.0 \\
5.3 \\
3.1 \\
7.5\end{array}$ & $\begin{array}{l}9.5 \\
5.1 \\
- \\
- \\
9.2\end{array}$ \\
\hline \multicolumn{7}{|c|}{$\begin{array}{l}\text { LSD }(0.05)=3.7 \\
\text { Testa }+ \text { cotyledon weight }\end{array}$} \\
\hline K-8 & $\begin{array}{c}20 \\
25 \\
30 \\
35 \\
30 / 25\end{array}$ & $\begin{array}{l}51.4 \\
51.4 \\
51.4 \\
51.4 \\
51.4\end{array}$ & $\begin{array}{l}46.3 \\
45.6 \\
40.6 \\
40.4 \\
43.6\end{array}$ & $\begin{array}{l}43.7 \\
37.2 \\
34.2 \\
27.8 \\
33.0\end{array}$ & $\begin{array}{l}38.4 \\
29.9 \\
31.7 \\
24.9 \\
31.0\end{array}$ & $\begin{array}{l}35.3 \\
28.5 \\
26.3 \\
23.3 \\
25.3\end{array}$ \\
\hline Yellow Puff & $\begin{array}{c}20 \\
25 \\
30 \\
35 \\
30 / 25\end{array}$ & $\begin{array}{l}37.9 \\
37.9 \\
37.9 \\
37.9 \\
37.9\end{array}$ & $\begin{array}{l}38.6 \\
34.5 \\
30.6 \\
32.6 \\
31.1\end{array}$ & $\begin{array}{l}29.4 \\
24.1 \\
25.0 \\
17.0 \\
25.9\end{array}$ & $\begin{array}{r}27.6 \\
14.3 \\
17.1 \\
6.2 \\
18.3\end{array}$ & $\begin{array}{c}22.4 \\
13.2 \\
- \\
- \\
21.5\end{array}$ \\
\hline $\operatorname{LSD}(0.05)=6.2$ & & & & & & \\
\hline
\end{tabular}

The slower germination rates of K-8 may be due to the compartmentalization of nutrient reserves in endosperm. Mobilization and absorption of the endosperm reserves by the cotyledons are required before they are available to the embryo. Yet, once made available, the supply of nutrients for rapid seedling growth is large. Clearly, K-8 initially mobilized a larger amount of reserves from the endosperm than Yellow Puff since testa weight declined more in K-8 than Yellow Puff between day 0 and day 4 (Table 3). The cotyledon weight of Yellow Puff declined more than K-8 during the same time period at all temperatures except $20^{\circ} \mathrm{C}$ (Table 3). At $35^{\circ} \mathrm{C}$
Yellow Puff cotyledon weight decreased rapidly due to increased respiration and reserve mobilization rates. Seedling death due to reserve depletion was seen by day 12 , with no seedlings surviving to day 16. High temperatures increased the rate of decline in seed nutrient reserves, with both species responding similarly to the various temperature treatments. Although $\mathrm{K}-8$ had more nutrient reserves than Yellow Puff, the seed reserves of both cultivars declined at similar rates (Table 3 ). Seed reserves were depleted by the 16 day harvest. Seedling death of Yellow Puff was greater than that of $\mathrm{K}-8$ at 30 and $35^{\circ} \mathrm{C}$, probably due to lower seed reserves in Yellow Puff.

Radicle dry weight increased rapidly from day 0 to day 4 at all temperatures but remained relatively unchanged after reaching ca. $2.7 \mathrm{mg} /$ seedling in K-8 and ca. $1.2 \mathrm{mg} /$ seedling in Yellow Puff (Table 4). Hypocotyl growth was slower during the period of rapid radicle growth, from 0 to 4 days at $20^{\circ} \mathrm{C}$ for both species, and greater after day 4 (Table 4 ). This agrees with Tadmor and Cohen

Table 4. Radicle and hypocotyl weight ( $\mathrm{mg}$ seedling ${ }^{-1}$ ) Leucaena leucocephala variety K-8 and $L$. retusa variety Yellow Puff seedlings as affected by temperature and time of imbibition.

\begin{tabular}{|c|c|c|c|c|c|}
\hline \multirow[b]{2}{*}{ Variety } & \multirow{2}{*}{$\begin{array}{l}\text { Temper- } \\
\text { ature }\end{array}$} & \multicolumn{4}{|c|}{ Time of imbibition (Days) } \\
\hline & & 4 & 8 & 12 & 16 \\
\hline & $\left({ }^{\circ} \mathrm{C}\right)$ & \multicolumn{4}{|c|}{$\ldots \ldots\left(\mathrm{mg}\right.$ seedling $\left.{ }^{-1}\right) \ldots \ldots$} \\
\hline $\begin{array}{l}\text { Radicle weight } \\
\text { K-8 }\end{array}$ & $\begin{array}{c}20 \\
25 \\
30 \\
35 \\
30 / 25\end{array}$ & $\begin{array}{l}1.3 \\
2.3 \\
2.8 \\
2.9 \\
2.4\end{array}$ & $\begin{array}{l}2.1 \\
2.3 \\
2.6 \\
2.5 \\
2.8\end{array}$ & $\begin{array}{l}2.8 \\
2.7 \\
2.9 \\
2.1 \\
3.0\end{array}$ & $\begin{array}{l}3.1 \\
3.0 \\
3.1 \\
2.6 \\
3.2\end{array}$ \\
\hline $\operatorname{LSD}(0.05)=0.7$ & $\begin{array}{c}20 \\
25 \\
30 \\
35 \\
30 / 25\end{array}$ & $\begin{array}{l}1.1 \\
1.4 \\
1.4 \\
1.4 \\
1.4\end{array}$ & $\begin{array}{l}1.3 \\
1.1 \\
1.5 \\
0.9 \\
1.4\end{array}$ & $\begin{array}{l}1.2 \\
1.1 \\
1.2 \\
0.1 \\
1.1\end{array}$ & $\begin{array}{l}1.3 \\
1.1 \\
- \\
- \\
-\end{array}$ \\
\hline $\begin{array}{l}\text { Hypocotyl weight } \\
\text { K-8 }\end{array}$ & $\begin{array}{c}20 \\
25 \\
30 \\
35 \\
30 / 5\end{array}$ & $\begin{array}{l}0.8 \\
3.2 \\
5.4 \\
5.6 \\
4.7\end{array}$ & $\begin{array}{l}4.4 \\
8.8 \\
8.7 \\
6.8 \\
9.7\end{array}$ & $\begin{array}{r}7.0 \\
11.0 \\
11.6 \\
8.5 \\
13.1\end{array}$ & $\begin{array}{l}10.1 \\
13.9 \\
12.7 \\
11.8 \\
13.2\end{array}$ \\
\hline $\operatorname{LSD}(0.05)=3.2$ & $\begin{array}{c}20 \\
25 \\
30 \\
35 \\
30 / 25\end{array}$ & $\begin{array}{l}0.3 \\
2.5 \\
4.8 \\
3.9 \\
5.2\end{array}$ & $\begin{array}{l}4.4 \\
7.1 \\
7.4 \\
3.2 \\
7.6\end{array}$ & $\begin{array}{l}5.8 \\
6.4 \\
7.4 \\
0.9 \\
5.3\end{array}$ & $\begin{array}{l}9.3 \\
6.9 \\
- \\
- \\
-\end{array}$ \\
\hline
\end{tabular}

(1968) who report that upon germination, the radicle of grasses and legumes elongates rapidly for a time, then suddenly ceases. The maximum radicle weight attained before radicle growth ceased was not affected by temperature.

Radicle dry weight was significantly affected by an interaction of time after imbibition and temperature. This can be partially explained by the slow increase in $\mathrm{K}-8$ radicle dry weight at $20^{\circ} \mathrm{C}$ and a substantial decline in Yellow Puff radicle dry weight by day 12 at $35^{\circ} \mathrm{C}$ (Table 4). A significant interaction of species and time after imbibition resulted from a greater increase in radicle dry weight for K-8 from 0-4 days and the reduction of values from 8-12 days for Yellow Puff (Table 4).

Preferential partitioning of nutrient reserves to the hypocotyl has been reported to continue until the hypocotyl emerges from the soil (Tadmor and Cohen 1968). In this study, hypocotyl elongation continued as long as seed reserves allowed. Temperature and time 
after imbibition differently affected hypocotyl growth of the 2 species studied. At $20^{\circ} \mathrm{C}$ hypocotyl growth of the 2 species was similar (Table 4). At $25^{\circ} \mathrm{C}$ and $30^{\circ} \mathrm{C}$ hypocotyl growth of Yellow Puff ceased after day 8, while K-8 continued to grow throughout the study. When germinated at $35^{\circ} \mathrm{C}$, Yellow Puff showed a loss in hypocotyl dry weight by day 8 , while K-8 exhibited hypocotyl weight gains through day 12 . However, at the $35^{\circ} \mathrm{C}$ treatment, both species appear to have exhausted seed reserves by 16 days after imbibition as indicated by the large number of dead seedlings in both species. The difference in hypocotyl growth over time between the 2 species, especially at the higher temperatures, probably results from the depletion of nutrient reserves in the smaller seeded species.

The partitioning of seed nutrient reserves between the radicle and hypocotyl in the dark grown seedlings were examined by observing the ratio of radicle dry weight to hypocotyl dry weight. There was no difference in the radicle/hypocotyl ratios of the 2 species in this study. The radicle/hypocotyl ratio was less than 1 for all harvest times and temperature combinations except the 4-day harvest at $20^{\circ} \mathrm{C}$ (Table 5). In this experiment, the initial period of

Table 5. Effect of temperature and time of imbibition on radicle/hypocotyl ratio of Leucaena seedlings.

\begin{tabular}{lcc}
\hline \hline Time of imbibition & Temperature & $\begin{array}{c}\text { Radicle/hypocotyl } \\
\text { ratio }\end{array}$ \\
\hline (days) & $\left({ }^{\circ}\right.$ C) & \\
4 & 20 & 3.2 \\
4 & 25 & 0.7 \\
4 & 30 & 0.4 \\
4 & 35 & 0.4 \\
4 & $30 / 25$ & 0.4 \\
8 & 20 & 0.4 \\
8 & 25 & 0.2 \\
8 & 30 & 0.2 \\
8 & 35 & 0.3 \\
8 & $30 / 25$ & 0.3 \\
12 & 20 & 0.3 \\
12 & 25 & 0.2 \\
12 & 30 & 0.2 \\
12 & 35 & 0.2 \\
12 & $30 / 25$ & 0.2 \\
16 & 20 & 0.2 \\
16 & 25 & 0.2 \\
16 & 30 & 0.2 \\
16 & 35 & 0.2 \\
16 & $30 / 25$ & 0.3 \\
LSD $(0.05)=0.4$ & & \\
\hline
\end{tabular}

partitioning of reserves to the radicle was completed well before the first harvest at most temperatures, and the preferential partitioning of reserves to the hypocotyl had begun to result in low radicle/hypocotyl ratios (Table 5). In contrast, the $20^{\circ} \mathrm{C}$ treatment decreased the rate of reserve mobilization, and by the first harvest, radicle weight still exceeded hypocotyl weight.

\section{Summary and Conclusions}

Yellow Puff exceeded K-8 in 2 measures of seed quality, maximum germination percent and germination rate; however, seedling elongation rate, which may more accurately assess seed vigor, was greater for K-8. The seed quality of both cultivars as assessed by maximum germination percent, germination rate, and seedling elongation appeared to be adequate. The rapid germination of Yellow Puff could encourage establishment in arid environments. However, where water is not limiting, $K-8$ could prove to be the more competitive due to the larger seed size and greater seedling reserves. Hybrids of the 2 species are now available and should be examined to determine their germination and seedling growth characteristics. It is possible that the rapid germination and rapid seedling elongation of the 2 species could be combined to improve seedling establishment, especially where moisture is limiting.

Partitioning of resources between the radicle and hypocotyl followed a biphasic pattern similar to that reported by other researchers. Initially, a high proportion of resources was allocated to the radicle. However, partitioning of resources soon shifted to the hypocotyl and radicle weight remained relatively unchanged while the hypocotyl grew rapidly. Lower temperatures delayed the shift in partitioning from the radicle to the hypocotyl. In spite of the initially rapid radicle growth, hypocotyl weight exceeded radicle weight and radicle/hypocotyl ratios were less than 0.5 by 4 days after imbibition at temperatures above $20^{\circ} \mathrm{C}$.

Partitioning of a large proportion of resources to the radicle does not appear to limit shoot growth in dark grown seedlings. Although partitioning of seed reserves could change when the seedling was exposed to light, partitioning of seed reserves in dark grown Leucaena seedlings appears to be determined by factors other than temperature. Further studies comparing the radicle and hypocotyl weights of dark and light grown seedlings should help clarify both the effect of light on resource partitioning and the photosynthetic ability in young, developing Leucaena seedlings.

\section{Literature Cited}

Beveridge, J.L., and C.P. Wilsie. 1959. Influence of depth of planting, seed size, and variey on emergence and seedling vigor in alfalfa. Agron. J. 51:731-734.

Carleton, A.E., and C.S. Cooper. 1972. Seed size effects upon seedling vigor of three forage legumes. Crop Sci. 12:183-186.

Cooksley, D.G. 1974. A study of preplanting herbicides, nitrogen, burning, and post-emergence cultivation on the establishment of Leucaena leucocephala cv. Peru. Queensland J. Agr. Anim. Sci. 31:271-278.

Cooper, C.S., M.A. Hughes, and R.L. Ditterline. 1980. Seedling length day 3-a simple rapid technique for evaluating seedling vigor of birdsfoot trefoil (Lotus corniculatus L.). J. Seed Tech. 5:17-25.

Correll, D.S., and M.C. Johnston. 1970. Manual of Vascular Plants in Texas. Texas Res. Found. Renner, Tex.

Gupta, S.K., P.S. Pathak, and R. Dev Roy. 1983. Seedling growth of Leucaena leucocephala (Lam.) De Wit, II. Effect of seed size. Indian J. Forest. 6:202-204.

Hicks, C.R. 1982. Fundamental concepts in the design of experiments. Holt, Reinhart, and Winston, N.Y.

Holliday, J., and P. Somasegaran. 1982. Nodulation, nitrogen fixation, an Rhizobium strain affinities in the genus Leucaena, p. 27-31. In: Leucaena research in the Asian-Pacific Region: Workshop Proc. Singapore, 23-26 Nov. 1982. Int. Devel. Res. Cen., Ottawa, Canada.

Jones, R.J., and R.A. Bray. 1982. Agronomic research in the development of Leucaena as a pasture legume in Australia, p. 41-48. In: Leucaena research in the Asian-Pacific region. Workshop Proc. Singapore, 23-26 Nov. 1982. Int. Devel. Res. Cen. Ottawa, Canada.

Lesniak, A.P., and E.H. Liu. 1981. Biological properties of Leucaeno leucocephala seed galactomannans. Leucaena Research Reports. 2:77-78.

Pathak, P.S., R. Deb Roy, and M.P. Rai. 1974. Autecology of Leucaena eucocephala (Lam.) De Wit. I. Seed polymorphism and germination. Trop. Eco. 15:1-10.

Reid, J., and H. Meier. 1973. Enzymic activities and galactomannan mobilization in germinating seeds of fenugreek. Planta 112:301-308.

Tadmor, N.H., and Y. Cohen. 1968. Root elongation in the preemergence stage of Mediterranean grasses and legumes. Crop Sci. 8:416-419.

Townsend, C.E. 1979. Associations among seed weight, seedling emergence, and planting depth in Cicer milkvetch. Agron. J. 71:410-414.

Whisenant, S.G., and D.N. Ueckert. 1982. Germination responses of Eysenhardtia texana and Leucaena retusa. J. Range Manage. 36:748-750.

Whisenant, S.G., D.N. Ueckert, and J.E. Huston. 1985. Evaluation of selected shrubs for arid and semiarid game ranches. J. Wildl. Manage. 49:524-527. 